\title{
A preliminary study on the serum protein response in canine babesiosis
}

\author{
R G Lobetti ${ }^{\mathrm{a}}$, A J Möhr ${ }^{\mathrm{a}}$, T Dippenaar ${ }^{\mathrm{b}}$ and E Myburgh ${ }^{\mathrm{b}}$
}

\begin{abstract}
Total serum protein, albumin, globulin, globulin fractions (alpha, beta and gamma globulins) and an acute-phase protein ( $\alpha 1$-acid glycoprotein) were evaluated in dogs with naturally occurring mild (Group 1), severe (Group 2) or complicated babesiosis (Group 3). Results showed that the total serum protein, albumin, $\mathrm{A} / \mathrm{G}$ ratio and $\alpha$ globulins were statistically different between Groups 1 and 2. There was no statistical difference between groups with total, $\beta$ and $\gamma$ globulins. The findings from this study suggest that dogs with mild and severe babesiosis had low total serum proteins, albumin, A/G ratio and $\alpha$ globulins; dogs with complicated babesiosis showed no typical serum protein changes or patterns; and that there was no evidence of an acute-phase response detectable on serum protein electrophoresis in any of the 3 groups. A marked acute-phase response was, however, present, as measured by the $\alpha 1$-acid glycoprotein, in all 3 groups. As this was a retrospective study, the possibility that the observed responses were due in part to concurrent disease could not be excluded.
\end{abstract}

Key words: $\alpha 1$-acid glycoprotein, acute phase proteins, Babesia canis, babesiosis, canine, protein electrophoresis, serum proteins.

Lobetti R G, Möhr A J, Dippenaar T, Myburgh E A preliminary study on the serum protein response in canine babesiosis. Journal of the South African Veterinary Association (2000) 71(1): 38-42 (En.). Department of Companion Animal Medicine, Faculty of Veterinary Science, University of Pretoria, Private Bag X04, Onderstepoort, 0110 South Africa.

\section{INTRODUCTION}

In South Africa, canine babesiosis is caused by the haemoprotozoan parasite, Babesia canis rossi ${ }^{10,22}$. Alterations in total serum proteins, serum protein quantification, serum protein electrophoretic changes and the acute-phase response in naturally occurring canine babesiosis have been poorly described. They have, however, been well described in pyrexia, haemolytic disease, some infectious diseases, acute inflammation and shock ${ }^{21}$, all of which are known to occur, in various combinations, in canine babesiosis. Alterations and patterns of changes in serum protein electrophoresis have been described in other haemoprotozoan diseases of dogs, cats, other domestic animals $^{6,14,21}$, and in malaria ${ }^{2,4}$ a disease that has many similarities to babesiosis ${ }^{7}$. There is thus reason to believe that serum protein alterations are likely to occur in canine babesiosis.

The interpretation of electrophoretograms in dogs suffering from babesiosis and with suspected concurrent disease is currently hampered by unfamiliarity with the electrophoretic changes in both

aDepartment of Companion Animal Medicine, Faculty of Veterinary Science, University of Pretoria, Private Bag X04, Onderstepoort, 0110 South Africa.

${ }^{b}$ Section of Clinical Pathology, Department of Companion Animal Medicine, Faculty of Veterinary Science, University of Pretoria.

Received: February 1999. Accepted: November 1999. uncomplicated and complicated babesiosis cases. Only 3 studies have documented serum protein electrophoresis changes in canine babesiosis ${ }^{9,11,20}$. However, these findings are not consistent, nor have the severity or complications of the disease been reported. One study was performed on experimental $\operatorname{dog}^{22}$, whereas the other 2 involved naturally occurring disease $\mathrm{e}^{9,11}$.

The purpose of this investigation was to retrospectively evaluate total serum protein, albumin, globulin, globulin fractions (alpha, beta and gamma globulins), and $\alpha 1$-acid glycoprotein $(\alpha \mathrm{GP})$, an acute phase protein, and to identify any patterns, if present, in dogs with naturally occurring B. canis infection. Ehrlichia canis titres were also determined to evaluate the possible effect of concurrent ehrlichiosis on the serum protein values. As this was a retrospective study, a number of shortcomings were identified: (1) concurrent disease could not conclusively be ruled out; (2) follow-up clinical, haematological and biochemical data were not available; and (3) Ehrlichia canis was not conclusively ruled out using polymerase chain reaction (PCR) techniques.

\section{MATERIALS AND METHODS}

The study was performed retrospectively on 29 stored serum samples of dogs with babesiosis, diagnosed on a stained, thin capillary blood smear (stained with Cams Quick stain (CA Milsch). Samples from 10 healthy dogs were used for comparison. All the dogs were from the Onderstepoort area presented at the Onderstepoort Veterinary Academic Hospital (OVAH) and all samples were collected before any treatment. Three groups of babesiosis cases were identified: mild uncomplicated, severe uncomplicated and complicated. Mild cases had mild to moderate anaemia (haematocrit 20-30 \%) with no clinical or biochemical signs of concurrent disease. Severe cases had severe anaemia (haematocrit $<15 \%$ ) with no clinical or biochemical signs of concurrent disease. Complicated cases had one or more of the following complications: cerebral signs, acute renal failure, acute respiratory distress syndrome, hypotensive shock, haemoconcentration, or immune-mediated haemolytic anaemia. This classification system is a clinically-based system as proposed by Jacobson and Clarke ${ }^{7}$. Samples from dogs that were presented to the OVAH for routine ovariohysterectomy and thus from the same area as the babesiosis cases, were used for comparison.

Standard methods were used for total serum protein, albumin, and globulin determination by the Section of Clinical Pathology of the Department of Medicine, Faculty of Veterinary Science, University of Pretoria. Total serum protein and albumin were determined using a Technicon RA-1000 system (Technicon Instruments Corporation). Total serum proteins were determined with the automated Biuret reagent method. The albumin was determined with the Bromcresol method, whereas the serum globulins were calculated by subtracting the albumin value from the total serum protein. The albumin-globulin $(A / G)$ ratio was calculated. Serum protein electrophoresis to identify alpha $(\alpha)$, beta $(\beta)$ and gamma $(\gamma)$ peaks was performed on a standard Beckman Microzone electrophoresis system, using a cellulose acetate membrane and Barbital buffer $(0.5$ ionic strength and $\mathrm{pH}$ 8.6). This system identifies $\alpha 1$ and $2, \beta 1$ and 2 , and $\gamma$ peaks. The $\alpha \mathrm{GP}$ was quantitatively determined using a commercially available radial immuno-diffusion test kit (Canine $\alpha 1 \mathrm{AG}$ 


\begin{tabular}{|c|c|c|c|c|c|c|c|c|c|c|c|c|}
\hline & & Breed & $\begin{array}{c}\text { Age } \\
\text { (months) }\end{array}$ & $\begin{array}{l}\text { Serum protein } \\
(\mathrm{g} / \ell)\end{array}$ & $\begin{array}{l}\text { Albumin } \\
(\mathrm{g} / \ell)\end{array}$ & $\begin{array}{l}\text { Globulin } \\
(\mathrm{g} / \ell)\end{array}$ & $\mathrm{A} / \mathrm{G}$ ratio & $\begin{array}{l}\text { Alpha } \\
(\mathrm{g} / \ell)\end{array}$ & $\begin{array}{l}\text { Beta } \\
(\mathrm{g} / \mathrm{l})\end{array}$ & $\begin{array}{c}\text { Gamma } \\
(\mathrm{g} / \ell)\end{array}$ & $\begin{array}{c}\alpha \mathbf{G P} \\
(\mu \mathrm{g} / \mathrm{m} \ell)\end{array}$ & $\begin{array}{l}\text { E. canis } \\
\text { titre }\end{array}$ \\
\hline \multicolumn{13}{|l|}{ GROUP 1} \\
\hline \multirow[t]{12}{*}{ Mild cases } & 1 & Bull terrier & 18 & 56.2 & 34.9 & 21.3 & 1.64 & 10.8 & 15.8 & 5.0 & 1400 & - \\
\hline & 2 & Toy pom & 36 & 49.2 & 32.9 & 16.3 & 2.02 & 11.2 & 11.9 & 3.5 & 1720 & - \\
\hline & 3 & Staffie $\times$ & 12 & 59.1 & 33.4 & 25.7 & 1.3 & 13.1 & 17.5 & 4.3 & 2580 & - \\
\hline & 4 & Doberman & 36 & 57.9 & 33.8 & 24.1 & 1.4 & 12.4 & 13.5 & 6.9 & 1300 & $\begin{array}{l}+ \\
\left(w^{\star \star \star}\right)\end{array}$ \\
\hline & 5 & Great Dane & 36 & 56.6 & 28.5 & 28.1 & 1.01 & 12.6 & 13.6 & 9.3 & 2840 & - \\
\hline & 6 & Bull terrier & 6 & 49.7 & 32.6 & 17.1 & 1.91 & 9.8 & 11.8 & 4.0 & 2200 & - \\
\hline & 7 & Boerboel & 12 & 52.4 & 28.3 & 24.1 & 1.17 & 10.8 & 13.4 & 7.1 & 2480 & $\begin{array}{l}+ \\
\left(s^{\star \star \star \star}\right)\end{array}$ \\
\hline & 8 & Staffie & 20 & 50.0 & 30.1 & 19.9 & 1.51 & 11.0 & 13.0 & 5.0 & 1370 & $+(s)$ \\
\hline & 9 & Chow $x$ & 36 & 50.4 & 32.8 & 17.6 & 1.86 & 9.4 & 13.8 & 5.0 & 1280 & - \\
\hline & 10 & GSD $\times$ & 132 & 66.9 & 36.1 & 30.8 & 1.17 & 13.7 & 17.1 & 8.0 & 340 & $+(w)$ \\
\hline & Mean & & 34.40 & 54.84 & 32.34 & 22.5 & 1.49 & 11.48 & 14.14 & 5.81 & 1751 & $N / A^{* *}$ \\
\hline & $\mathrm{SD}^{*}$ & & 36.24 & 5.63 & 2.95 & 4.89 & 0.34 & 1.41 & 1.99 & 1.91 & 766.79 & $\mathrm{~N} / \mathrm{A}$ \\
\hline \multicolumn{13}{|l|}{ GROUP 2} \\
\hline \multirow[t]{12}{*}{ Severe cases } & 1 & Labrador & 24 & 49.0 & 21.5 & 27.5 & 0.78 & 9.8 & 9.7 & 13.8 & 2450 & $+(w)$ \\
\hline & 2 & Dalmatian & 156 & 54.7 & 30.8 & 23.9 & 1.29 & 9.9 & 14.2 & 5.3 & 2120 & - \\
\hline & 3 & Spaniel & 10 & 55.1 & 24.9 & 30.2 & 0.82 & 11.3 & 9.7 & 16.0 & 2180 & $+(\mathrm{s})$ \\
\hline & 4 & Staffie $\times$ & 36 & 77.3 & 25.2 & 52.1 & 0.48 & 8.8 & 16.3 & 32.5 & 2180 & $+(s)$ \\
\hline & 5 & Ridgeback $\times$ & 9 & 77.0 & 20.7 & 52.3 & 0.4 & 11.6 & 13.8 & 32.5 & 1300 & - \\
\hline & 6 & Rottweiler & 108 & 61.5 & 25.4 & 36.1 & 0.7 & 13.0 & 15.8 & 13.7 & 2840 & $+(w)$ \\
\hline & 7 & Pug & 5 & 47.6 & 28.3 & 19.3 & 1.47 & 12.2 & 14.6 & 3.3 & 2450 & $+(w)$ \\
\hline & 8 & Boerboel & 36 & 51.0 & 19.4 & 31.6 & 0.61 & 10.3 & 13.9 & 12.1 & 2240 & $+(w)$ \\
\hline & 9 & Fox terrier & 5 & 39.4 & 18.8 & 20.6 & 0.91 & 9.8 & 8.3 & 6.6 & 2840 & $+(s)$ \\
\hline & 10 & Labrador & 5 & 45.3 & 26.5 & 18.8 & 1.41 & 11.7 & 8.7 & 5.7 & 1820 & - \\
\hline & Mean & & 39.4 & 55.39 & 24.15 & 31.24 & 0.88 & 10.84 & 12.5 & 14.15 & 2242 & $\mathrm{~N} / \mathrm{A}$ \\
\hline & SD & & 51.53 & 12.04 & 3.94 & 12.39 & 0.38 & 1.31 & 3.05 & 10.57 & 458.23 & $\mathrm{~N} / \mathrm{A}$ \\
\hline \multicolumn{13}{|l|}{ GROUP 3} \\
\hline \multirow[t]{11}{*}{ Complicated cases } & 1 & Maltese & 18 & 55.3 & 28.1 & 27.2 & 1.03 & 13.6 & 11.4 & 9.3 & 1680 & - \\
\hline & 2 & GSD & 5 & 46.2 & 21.1 & 25.1 & 0.84 & 10.2 & 6.8 & 11.1 & 1860 & - \\
\hline & 3 & Bull terrier & 36 & 65.0 & 36.5 & 28.5 & 1.28 & 12.7 & 20.2 & 9.7 & 1220 & - \\
\hline & 4 & Bull terrier & 54 & 74.8 & 45.3 & 29.5 & 1.54 & 17.7 & 25.5 & 7.1 & 2800 & $+(w)$ \\
\hline & 5 & Staffie & 108 & 49.4 & 26.6 & 22.8 & 1.17 & 10.6 & 12.6 & 6.1 & 1750 & $+(\mathrm{s})$ \\
\hline & 6 & Boerboel & 18 & 70.2 & 37.1 & 33.1 & 1.12 & 16.2 & 20.0 & 7.2 & 1640 & - \\
\hline & 7 & Bull dog & 36 & 56.5 & 26.6 & 29.9 & 0.89 & 12.5 & 21.4 & 8.8 & 620 & - \\
\hline & 8 & GSD $\times$ & 8 & 47.4 & 27.3 & 20.1 & 1.36 & 13.2 & 7.8 & 6.6 & 2660 & - \\
\hline & 9 & Staffie & 20 & 45.2 & 16.6 & 28.6 & 0.58 & 11.5 & 10.3 & 11.3 & 1040 & $+(w)$ \\
\hline & Mean & & 33.67 & 56.66 & 29.46 & 27.2 & 1.09 & 13.13 & 15.11 & 8.57 & 1696.67 & $\mathrm{~N} / \mathrm{A}$ \\
\hline & $\mathrm{SD}$ & & 31.83 & 10.97 & 8.78 & 3.95 & 0.29 & 2.46 & 6.73 & 1.92 & 706.67 & $\mathrm{~N} / \mathrm{A}$ \\
\hline \multicolumn{13}{|l|}{ GROUP 4} \\
\hline \multirow[t]{12}{*}{ Healthy } & 1 & Staffie $\times$ & 60 & 67.4 & 34 & 33.4 & 1.02 & 15.7 & 19.1 & 6.8 & 480 & - \\
\hline & 2 & Terrier $\times$ & 36 & 77.7 & 41.5 & 36.2 & 1.15 & 17 & 17.6 & 3.9 & 440 & $+(w)$ \\
\hline & 3 & Boxer & 48 & 68.4 & 29.6 & 38.8 & 0.76 & 12.6 & 26.9 & 3.8 & 590 & - \\
\hline & 4 & Boxer & 18 & 57 & 31.9 & 25.1 & 1.27 & 10.8 & 14.2 & 6.1 & 400 & - \\
\hline & 5 & Boxer & 36 & 72 & 37.2 & 34.8 & 1.07 & 15.2 & 20.6 & 5.6 & 400 & - \\
\hline & 6 & Border collie & 84 & 74.3 & 34.8 & 39.5 & 0.88 & 15.2 & 26.2 & 5.5 & 460 & $+(w)$ \\
\hline & 7 & Staffie & 20 & 66.6 & 41.1 & 25.5 & 1.61 & 15.1 & 14.3 & 6.6 & 660 & - \\
\hline & 8 & Terrier $\times$ & 6 & 59.1 & 38.6 & 20.5 & 1.88 & 13.4 & 10.3 & 4.1 & 360 & - \\
\hline & 9 & Chow & 26 & 71.5 & 43.6 & 27.9 & 1.56 & 16 & 13.8 & 7.8 & 680 & - \\
\hline & 10 & GSD & 16 & 61.7 & 34.9 & 26.8 & 1.3 & 11.4 & 15.9 & 7.4 & 620 & $+(w)$ \\
\hline & Mean & & 35 & 67.57 & 36.72 & 30.85 & 1.25 & 14.24 & 17.89 & 5.76 & 509 & $N / A$ \\
\hline & SD & & 23.56 & 6.68 & 4.49 & 6.51 & 0.35 & 2.07 & 5.42 & 1.45 & 117.80 & $\mathrm{~N} / \mathrm{A}$ \\
\hline
\end{tabular}

*Standard deviation; ${ }^{* *}$ not applicable; ${ }^{* * *}$ weakly positive; ${ }^{* * *}$ strongly positive.

plate, Cardiotech Services).

Ehrlichia canis titres were performed with a standard canine ehrlichiosis fluorescent antibody substrate slide using the Oklahoma strain as antigen and fluorescein conjugated anti-dog IgG (VMRD). A positive reaction was taken as $\geq 1: 40$, with sera not reactive at this dilution being regarded as negative ${ }^{12}$.

Statistical analysis of the data was per- formed on a commercial statistical software package (SigmaStat software, Jandel Scientific Software). The data were compared using the Kruskal-Wallis 1-way analysis of variance on ranks comparing the serum protein parameters between the groups. The Tukey test was used for pairwise comparisons between individual parameters within the groups. Significance was set at $P<0.05$.

\section{RESULTS}

Twenty-nine babesiosis cases were evaluated (Table 1): Group 1 comprised 10 mild uncomplicated cases; Group 2, 10 severe uncomplicated cases; and Group 3, 9 complicated cases. Ten healthy dogs were for comparison (Group 4). The complications recorded in this study were immune-mediated haemolytic anaemia (2), haemoconcentration (3), acute respi- 
ratory distress syndrome (2) and hypotensive shock (2).

Total serum protein was statistically different between Groups 1 and 2 and Group 4; Groups 1 and 2 showed a lower total serum protein value. A similar result was evident with albumin and the $\mathrm{A} / \mathrm{G}$ ratio. There was no statistical difference in the total globulin values (Fig. 1).

The $\alpha$ globulins were statistically significantly lower in Groups 1 and 2 than in Group 4. There was, however, no statistical difference between Groups 1, 2 and 3, and there were no specific patterns with the various complications. Neither the serum $\beta$ nor $\gamma$ globulins were significantly different between the 3 babesiosis groups (Fig. 2).

Twenty-seven of the 29 babesiosis cases showed a massive $\alpha$ GP response, which was statistically significant, when compared to Group 4. There was, however, no statistical difference in the $\alpha \mathrm{GP}$ response between Groups 1, 2, and 3 (Fig. 3).

All groups showed positive E. canis titres: 4 of the dogs in Group 1, 7 of the dogs in Group 2, and 3 dogs in both Groups 3 and 4 . At a titre of $\geq 1: 40$, taken as positive, only 6 dogs were strongly positive. Of the E. canis-positive dogs, only 1 dog in Group 2 showed a corresponding increase in the total and $\gamma$ globulins.

There was no age difference between the 4 groups. The mean age for all groups was approximately 35 months. Group 3 appeared to contain more fighting breeds (bull terriers and Staffordshire terriers) than the other groups.

\section{DISCUSSION}

The results of this study suggest that dogs with mild and severe babesiosis had low total serum proteins, albumin, $\mathrm{A} / \mathrm{G}$ ratio and $\alpha$ globulins, whereas dogs with complicated babesiosis showed no typical serum protein changes or patterns. It also appeared that dogs with babesiosis showed no evidence of an acute-phase response detectable on serum protein electrophoresis. A massive acute-phase response, as measured by the $\alpha \mathrm{GP}$, was, however, present in all the babesiosis groups.

Maegraith ${ }^{9}$, in a study of pathological processes in B. canis infection, identified a decrease in serum albumin concentration with a concomitant increase in serum globulin concentration, and it was postulated that the latter might be due to increased immunoglobulin production. Quantification of the various globulin fractions was, however, not performed to test this hypothesis. The decreased albumin concentration corresponds with the findings in this study. It is, however,

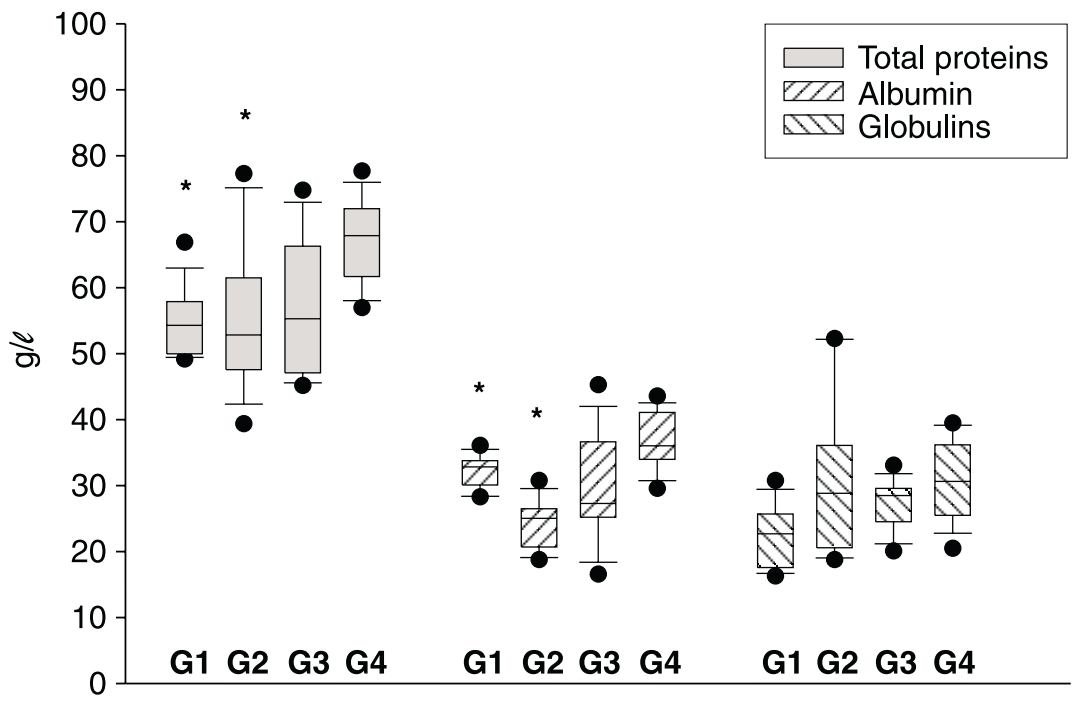

Fig. 1: Total serum proteins, albumin, and globulins for the $\mathbf{4}$ groups. Data are shown as median (horizontal line within box), 25th and 75th percentiles (horizontal ends of boxes), and 10th and 90th percentiles (T-bars). Significant group differences are indicated by an asterisk. Black dots represent outliers. G1-G4 represents Groups 1-4.

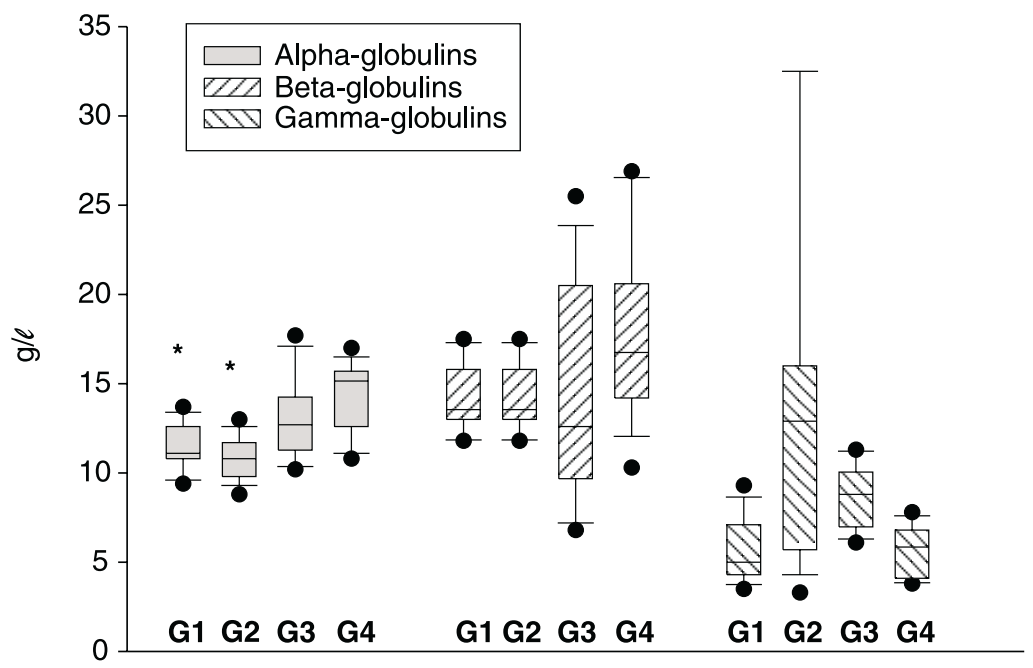

Fig. 2: Serum protein fractions for the $\mathbf{4}$ groups. Data are shown as median (horizontal line within box), 25th and 75th percentiles (horizontal ends of boxes), and 10th and 90th percentiles (T-bars). Significant group differences are indicated by an asterisk. Black dots represent outliers. G1-G4 represents Groups 1-4.

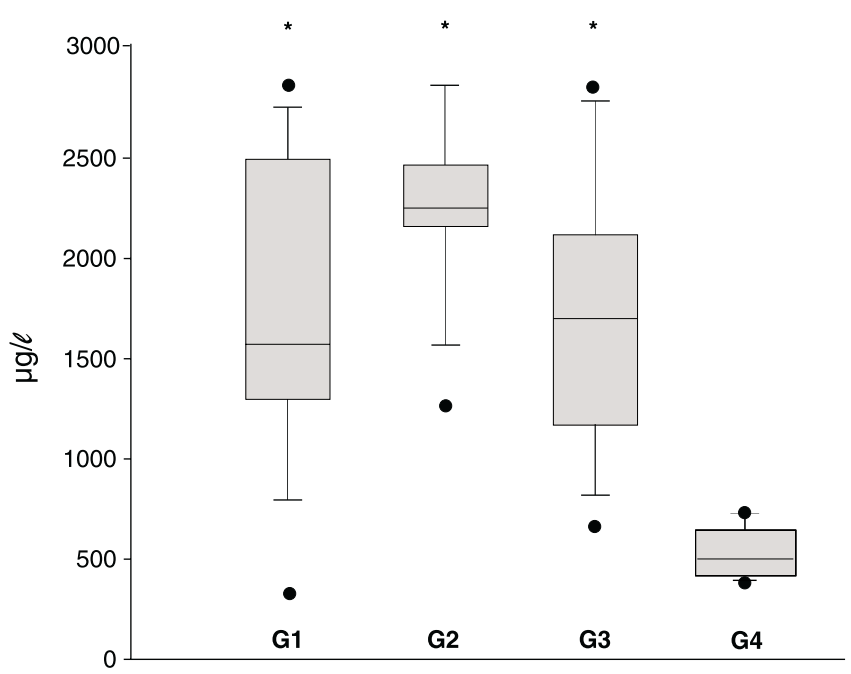

Fig. 3: $\alpha 1$-acid glycoprotein for the $\mathbf{4}$ groups. Data are shown as median (horizontal line within box), 25th and 75th percentiles (horizontal ends of boxes), and 10th and 90th percentiles (T-bars). Significant group differences are indicated by an asterisk. Black dots represent outliers. G1-4 represents Groups 1-4. 
difficult to correlate the globulin findings in Maegraith's study, as the serum protein fractions were not quantified and the babesiosis cases were not classified into mild, severe, or complicated forms. In another study ${ }^{20}$, the electrophoretic changes in 6 puppies with experimentally induced babesiosis included a decrease in the albumin fraction and increased $\alpha 1$, $\alpha 2$ and $\gamma$ globulins, while $\beta$ globulins remained unchanged. In this study, there was a decrease in the albumin fraction, but there was no increase in the $\alpha$ globulins. In a study by Malherbe ${ }^{11}$, dogs with unclassified babesiosis showed a decrease in serum albumin, no significant change in $\alpha 1$ globulin, a significant decrease in $\alpha 2$ globulin, and a significant rise in $\gamma$ globulin fractions. The $\beta$ globulin levels were not recorded, as free haemoglobin was considered to have falsely elevated this fraction. The decrease in albumin corresponds with the findings in this study.

Similar serum protein changes have been described in other haemoprotozoal infections. Feline babesiosis has been associated with decreases in $\alpha$ and $\beta$ globulins, and an increase in $\gamma$ globulins ${ }^{6}$, whereas feline haemobartonellosis has been associated with increases in $\alpha 3, \beta 2$, and occasionally $\gamma$ globulins ${ }^{21}$. The serum protein electrophoretic pattern in guinea-pigs and horses infected with Trypanosoma evansi revealed a highly significant decrease in albumin levels and an increase in $\gamma$ globulins, leading to a very low $\mathrm{A} / \mathrm{G}$ ratio. No significant differences in total protein levels between healthy and infected animals were registered. Likewise, $\alpha$ globulins were not significantly affected. A decrease in $\beta$ globulins was observed in 1 horse and in guinea pigs with experimental infection, while in horses with natural infections this decrease was not constant ${ }^{14}$. In one malaria study it was shown that there was an increase in the $\gamma$ globulins, a decrease in the serum albumin, and no consistent pattern of change in either the $\alpha$ or $\beta$ globulins ${ }^{4}$. The decrease in the serum albumin agrees with the present study. In humans with Plasmodium falciparum infection there is a decrease in the $A / G$ ratio, an increase in the $\alpha$ and $\gamma$ globulins and a decrease in the $\beta$ globulins ${ }^{2}$. The $\mathrm{A} / \mathrm{G}$ ratio changes agree with those in this study.

The acute-phase response occurs during the early stage of infection, tissue injury or immunological disorders ${ }^{24}$. Acute-phase proteins (APP) are serum proteins identifiable by electrophoresis in the $\alpha$ globulin zone, which increase in concentration during the acute-phase response to inflammation or infection ${ }^{5}$. The systemic reaction of the acute-phase response includes dramatic changes in
APP concentrations, primarily due to increased hepatic APP production ${ }^{24}$.

As the incubation period of canine babesiosis is $10-21$ days $^{1}$, it would have been expected that an increase in the $\alpha$ globulins (representing APP) would have been evident on serum protein electrophoresis. The lack of $\alpha$ globulin elevations in all 3 groups of canine babesiosis cases in this study may be indicative of no APP; however, the significant elevation of $\alpha \mathrm{GP}$ indicated a massive increase in at least one APP. Therefore, serum protein electrophoresis may not be sensitive enough to detect elevated APP, as was demonstrated in this study, presumably because the concentration was insufficient to raise the total $\alpha$ globulin value above the normal range. In this study, complicated cases had the highest mean $\alpha$ globulin value of the 3 groups, although none of the dogs showed an increase in the $\alpha$ globulin values.

Inflammatory changes following infection are central to the clinical manifestation of disease, and APP alterations may reflect the severity of inflammatory damage $^{18}$. Complicated babesiosis has been suggested to be the consequence of dogs developing the systemic inflammatory response syndrome (SIRS), and the multiple organ dysfunction syndrome (MODS), both of which are cytokinemediated phenomena ${ }^{7}$. Pyrexia also develops, and is attributed to the release of endogenous pyrogens from erythrolysis, parasite destruction, and activation of inflammatory mediators ${ }^{1,7}$.

A study correlating serum cytokine activity with APP levels in dogs with acute inflammation demonstrated significantly raised serum interleukin-6 (IL-6) and tumour necrosis factor (TNF) levels, which preceded the APP increase ${ }^{24}$. Dogs that develop complicated babesiosis (SIRS or MODS) may be expected to show similar APP alterations as was demonstrated in this study.

An increased blood fibrinogen concentration in the early phase of experimental canine babesiosis infection has also been linked to the acute-phase response ${ }^{19}$. In human Falciparum malaria, cytokinemediated activation of hepatocytes induces acute-phase responses, which may contribute to the stabilisation of parasitaemia $^{23}$.

Higher serum globulin concentrations have been associated with death in dogs with babesiosis that have an admission haematocrit of $\geq 30 \%{ }^{17}$. It was postulated that if these globulins were acute phase proteins, they could reflect an overwhelming inflammatory process and/or be a reflection of tissue destruction. Although the haematocrits in all but 1 of the dogs in our study were below $30 \%$, and therefore reflect a different disease sub-group, the postulated reasons for increases in acute phase proteins may nevertheless hold true. In the same study, it was suggested that, if the increased globulins in this disease sub-group represented immunoglobulins, the theory of an 'over-enthusiastic immune response' would be strengthened ${ }^{17}$. The lack of a statistically significant elevation in $\gamma$ globulins in this study does not support the latter hypothesis.

Marked increases in 2 APP (C-reactive protein (CRP) and haptoglobin) have been demonstrated in dogs following infection with another haemoprotozoan parasite, Trypanosoma brucei. The highest levels of CRP were observed immediately after the peak of parasitaemia ${ }^{15}$. Measurement of APP in acute canine ehrlichiosis demonstrated significant elevations in CRP and $\alpha$ GP 4- 6 days post-exposure ${ }^{18}$.

Albumin has been termed a negative APP, and its serum concentration may decrease during the acute-phase response ${ }^{22}$. Significant decreases in serum albumin concentrations have been shown to follow significant increases in serum IL-6 and TNF activities ${ }^{24}$. In agreement with previous studies ${ }^{9,11,20}$, the mean albumin values for all 3 babesiosis groups in this study were lower than the comparison group, with a statistically lower albumin value in Groups 1 and 2 as compared to that group. It has been reported that albumin values decrease with advancing age $^{8}$. As the mean was approximately 35 months in this study, the decreased albumin values were attributed to the babesiosis alone.

Ehrlichia canis infection has no pathognomonic clinical signs, and typical E.canis morulae in monocytes can only be found during the acute phase following infection, rendering it a difficult disease to diagnose $^{12,16}$. None of the dogs in this study revealed E. canis morulae on peripheral blood smear, nor had any haematological changes or clinical signs suggestive of ehrlichiosis. Although the majority of the dogs had positive E.canis titres, only 1 dog in the severe uncomplicated group showed a corresponding increase in the serum globulins and $\gamma$ globulins that could indicate concurrent ehrlichiosis. A study performed in the Bloemfontein area of South Africa identified $42 \%$ of apparently healthy dogs with significant antibody titres $(\geq 1: 64)$ against E.canis $^{16}$, and a similar study conducted in Zimbabwe reported the same figure of $42 \%$ seropositivity $(\geq 1: 40)$ against E.canis in apparently healthy dogs ${ }^{12}$. It has been reported that hyperglobulinaemia is commonly detected in all phases of this 
disease $^{12}$. The Zimbabwean study, however, identified hyperglobulinaemia in only $5 \%$ (2/39) of these dogs, while none of the dogs showed hypoalbuminaemia. In a study conducted on dogs infected with B.canis and E.canis, the prevalence of hyperglobulinaemia was found to be significantly higher in dogs with babesiosis that had a significant E.canis antibody titre $(\geq 1: 20)$, compared to dogs with significant antibodies to E.canis without concurrent babesiosis ${ }^{13}$. This suggests that the presence or absence of a significant E.canis titre does not significantly affect the prevalence of hyperglobulinaemia in dogs with babesiosis. The latter study also failed to demonstrate any relationship between E.canis antibody titre, and abnormal laboratory values and/or the presence or absence of clinical signs ${ }^{13}$. A study performed in Virginia in the USA found a significant E.canis antibody titre $(\geq 1: 64)$ in $38 \%(28 / 74)$ of dogs studied ${ }^{3}$. However, PCR analysis on blood samples from these dogs gave negative results for E.canis in all samples. The results do, however, indicate that E.canis serology is much less specific than previously believed. We therefore do not believe that the positive E.canis titres in this study necessarily reflect concurrent ehrlichiosis, or that such co-infection, if indeed present, would appreciably interfere with or skew the results of this study. The effects of other concurrent diseases could not be evaluated, but it is unlikely that all of the dogs would have been suffering from concurrent diseases with similar effects.

The results of this study suggest that dogs with mild and severe babesiosis have low total serum proteins, albumin, $\mathrm{A} / \mathrm{G}$ ratio and $\alpha$ globulins; dogs with complicated babesiosis reveal no typical serum protein changes or patterns; and no dogs with babesiosis evince an acutephase response detectable by serum protein electrophoresis. There is, however, evidence of a significant APP response in the mild, severe and complicated canine babesiosis, which did not correlate with the $\alpha$ globulin concentrations. From this preliminary study, a prospective, larger, controlled study is necessary so that possible concurrent disease can be ruled out and follow-up clinical, haematological and biochemical data can be collected to follow the serum protein trends.

\section{ACKNOWLEDGEMENTS}

The authors would like to thank the South African Veterinary Foundation and the Pet Memorial fund for partial sponsorship of this project, and Mrs E. Stylianides, Department of Veterinary Tropical Diseases, Faculty of Veterinary Science, University of Pretoria, for her work in running the Ehrlichia titres.

\section{REFERENCES}

1. Breitschwerdt E B 1990 Babesiosis. In Greene C G (ed.) Infectious diseases of the dog and cat. W B Saunders Company, Philadelphia: 796-803

2. Collins WE, Contacos P G, Skinner JC, Harrison A J, Gell L S 1971 Patterns of antibodies and serum proteins in experimentally induced human malaria. Transactions of the Royal Society of Tropical Medicine and Hygiene 65: 43-58

3. Dawson J E, Biggie K L, Warner C K, Cookson K, Jenkins S, Levine J F, Olson J G 1996 Polymerase chain reaction evidence of Ehrlichia chafeensis, an etiologic agent of human ehrlichiosis, in dogs from southeast Virginia. American Journal of Veterinary Research 57: 1175-1179

4. Desowitz R S, Pavanand K, Vacharaphorn D 1968 Serum protein alterations in Plasmodium coatneyi malaria: a comparison of cellulose acetate and polyacrylamide electrophoretic patterns. Annals of Tropical Medicine and Parasitology 62: 210-217

5. Eckersall P D, Conner J G 1988 Bovine and canine acute phase proteins. Veterinary Research and Communication 12: 169-178

6. Futter G J, Belonje P C, Van den Berg A, Van Rijswijk A W 1981 Studies on feline babesiosis. 4 Chemical pathology; macroscopic and microscopic post mortem findings. Journal of the South African Veterinary Association 52: 5-14

7. Jacobson L J, Clark I 1994 The pathophysiology of canine babesiosis: new approaches to an old puzzle. Journal of the South African Veterinary Association 65: 134-145

8. Kaneko J J 1989 Serum proteins and the dysproteinaemias. In Kaneko J J (ed.) Clinical biochemistry of domestic animals. Academic Press, San Diego: 142-165

9. Maegraith B, Gilles H M, Devakul K 1957 Pathological processes in Babesia canis infections. Zeitschrift für Tropenmedizin und Parasitologie 8: 485-514

10. Malherbe WD 1956 The manifestations and diagnosis of Babesia infections. Annals of the New York Academy of Science 64: 128-146

11. Malherbe W D 1966 A clinico-pathological study of Babesia canis infection in dogs. PhD thesis, University of Pretoria
12. Matthewman L A, Kelly P J, Mahan S M, Semu D, Tagwira M, Bobade P A, Brouqui P, Manson P R, Raoult D 1993 Western blot and indirect fluorescent antibody testing for antibodies reactive with Ehrlichia canis in sera from apparently healthy dogs in Zimbabwe. Journal of the South African Veterinary Association 64: 111-115

13. Matthewman L A, Kelly P J, Bobade P A, Tagwira M, Manson P R, Majok A, Brouqui P, Raoult D 1993 Infections with Babesia canis and Ehrlichia canis in dogs in Zimbabwe. The Veterinary Record 133: 344-346

14. Monzon C M, Villavicencio V I 1990 Serum proteins in guinea pigs and horses infected with Trypanosoma evansi. Veterinary Parasitology 36: 295-301

15. Ndung' $u$ J M, Eckersall P D, Jennings F W 1991 Elevation of the concentration of acute phase proteins in dogs infected with Trypanosoma brucei. Acta Tropica 49: 77-86

16. Pretorius A-M, Kelly P A 1998 Serological survey for antibodies reactive with Ehrlichia canis and E. chafeensis in dogs from the Bloemfontein area, South Africa. Journal of the South African Veterinary Association 69: 126-128

17. Reyers F, Leisewitz A L, Lobetti R G, Milner R J, Jacobson L S, Van Zyl M 1998 Canine babesiosis in South Africa: more than one disease. Does this serve as a model for falciparum malaria? Annals of Tropical Medicine and Parasitology 92: 503-511

18. Rikihisa $Y$, Yamamoto $S$, Kwak I, Iqbal Z, Kociba G, Mott J, Chichanasiriwithaya W J 1994 C-reactive protein and alpha 1-acid glycoprotein levels in dogs infected with Ehrlichia canis. Clinical Microbiology 32: 912-917

19. Schetters T P M, Moubri K, Precigout E, Kleuskens J, Scholtes N C, Gorenflot A 1997 Different Babesia canis isolates, different diseases. Parasitology 115: 485-493

20. Tella A, Maegraith B G 1965 Physiopathological changes in primary acute bloodtransmitted malaria and Babesia infections. II. A comparative study of serum protein levels in infected rhesus monkeys, mice and puppies. Annals of Tropical Medicine and Parasitology 59: 153-158

21. Taylor J M 1983 Electrophoresis of canine and feline serum. Modern Veterinary Practice 64: 154-157

22. Uilenberg G, Franssen F F J, Perie N M 1989 Three groups of Babesia canis distinguished and a proposal for nomenclature. Veterinary Quarterly 11: 33-40

23. Urquahart A D 1994 Putative pathophysiological interactions of cytokines and phagocytic cells in severe human falciparum malaria. Clinical Infectious Diseases 19: 117-131

24. Yamashita K, Fujinaga T, Miyamoto T, Hagio M, Izumisawa Y, Kotani T J 1994 Canine acute-phase response: relationship between serum cytokine activity and acute phase protein in dogs. Japanese Journal of Veterinary Medicine and Science 56: 487-492 